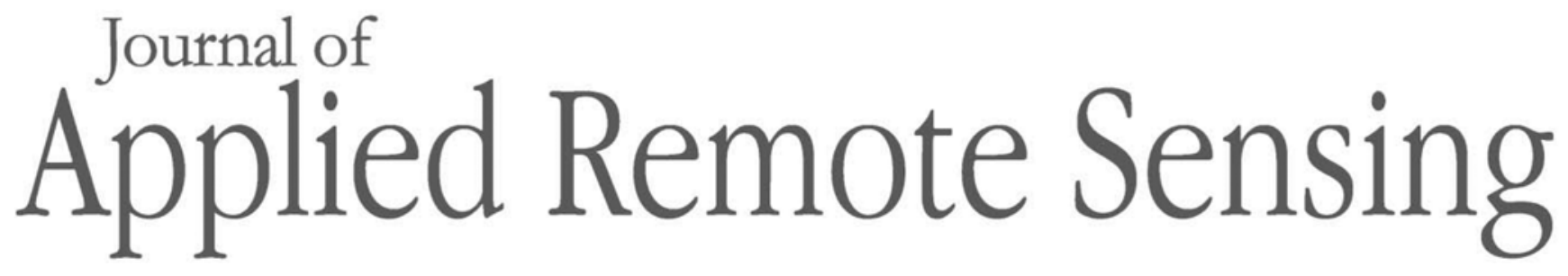

RemoteSensing.SPIEDigitalLibrary.org

\title{
Methane optical density measurements with an integrated path differential absorption lidar from an airborne platform
}

\author{
Haris Riris \\ Kenji Numata \\ Stewart $\mathrm{Wu}$ \\ Brayler Gonzalez \\ Michael Rodriguez \\ Stan Scott \\ Stephan Kawa \\ Jianping Mao
}

Haris Riris, Kenji Numata, Stewart Wu, Brayler Gonzalez, Michael Rodriguez, Stan Scott, Stephan Kawa, Jianping Mao, "Methane optical density measurements with an integrated path differential absorption lidar 


\title{
Methane optical density measurements with an integrated path differential absorption lidar from an airborne platform
}

\author{
Haris Riris, ${ }^{\mathrm{a}, *}$ Kenji Numata, ${ }^{\mathrm{a}}$ Stewart $\mathrm{Wu},{ }^{\mathrm{a}}$ Brayler Gonzalez, ${ }^{\mathrm{a}}$ \\ Michael Rodriguez, ${ }^{b}$ Stan Scott, ${ }^{a}$ Stephan Kawa, ${ }^{a}$ and Jianping Maoc \\ ${ }^{a}$ NASA Goddard Space Flight Center, Greenbelt, Maryland, United States \\ ${ }^{\mathrm{b}}$ Sigma Space Corporation, Lanham, Maryland, United States \\ ${ }^{c}$ University of Maryland, Earth System Science Interdisciplinary Center (ESSIC), College Park, \\ Maryland, United States
}

\begin{abstract}
We report on an airborne demonstration of atmospheric methane $\left(\mathrm{CH}_{4}\right)$ measurements with an integrated path differential absorption lidar using an optical parametric amplifier and optical parametric oscillator laser transmitter and sensitive avalanche photodiode detector. The lidar measures the atmospheric $\mathrm{CH}_{4}$ absorption at multiple, discrete wavelengths near $1650.96 \mathrm{~nm}$. The instrument was deployed in the fall of 2015, aboard NASA's DC-8 airborne laboratory along with an in situ spectrometer and measured $\mathrm{CH}_{4}$ over a wide range of surfaces and atmospheric conditions from altitudes of 2 to $13 \mathrm{~km}$. We will show the results from our flights, compare the performance of the two laser transmitters, and identify areas of improvement for the lidar. () The Authors. Published by SPIE under a Creative Commons Attribution 3.0 Unported License. Distribution or reproduction of this work in whole or in part requires full attribution of the original publication, including its DOI. [DOI: 10.1117/1.JRS.11.034001]
\end{abstract}

Keywords: lidar; spectroscopy; methane; optical parametric amplifiers; optical parametric oscillators; airborne instruments.

Paper 170451 received May 26, 2017; accepted for publication Aug. 3, 2017; published online Sep. 1, 2017.

\section{Introduction}

Methane $\left(\mathrm{CH}_{4}\right)$ is the second most important anthropogenic greenhouse gas (GHG) with a higher radiative forcing potential than carbon dioxide $\left(\mathrm{CO}_{2}\right)$ on a per molecule basis, ${ }^{1}$ making anthropogenic $\mathrm{CH}_{4}$ a critical target for mitigation. The current $\mathrm{CH}_{4}$ global mixing ratio is 1852 parts per billion (ppb). ${ }^{2,3}$ Anthropogenic $\mathrm{CH}_{4}$ is responsible for a significant portion of the global warming produced by all well-mixed GHGs and contributes to the formation of ozone, ${ }^{4}$ another GHG and air pollutant.

Despite the critical importance of $\mathrm{CH}_{4}$ for climate, the existing $\mathrm{CH}_{4}$ observing network has proven inadequate to constrain global, regional, and sectoral sources, and explain observed trends and variation in atmospheric $\mathrm{CH}_{4}$ over the last few decades. Therefore, there is a critical need for $\mathrm{CH}_{4}$ observations for constraining the strength and distribution of methane's sources, including natural (e.g., wetlands) and anthropogenic (e.g., energy sector) ones. For instance, much of the year-to-year variations in methane's global growth rate are likely from variations in wetland emissions and part of the recent increasing trend in methane's growth rate may be associated with increased energy extraction activities. ${ }^{5,6}$ An adequate $\mathrm{CH}_{4}$ observing network is necessary to monitor the interaction between the carbon cycle and climate change, such as the potential release of $\mathrm{CH}_{4}$ from stored carbon reservoirs (e.g., Arctic and boreal soils) and changes in natural emissions. The current $\mathrm{CH}_{4}$ observing network does not provide the necessary data to understand and constrain methane's sources, such as from permafrost thaw and wetlands, which challenges our ability to make confident projections of future climate. The importance of

*Address all correspondence to: Haris Riris, E-mail: haris.riris@nasa.gov 
measuring $\mathrm{CH}_{4}$ is also reflected in the last National Research Council Decadal Survey for Earth Science $^{7}$ and the recent report by the Carbon Climate Workshop. ${ }^{8}$

Our current understanding of $\mathrm{CH}_{4}$ distributions and processes is founded mostly on precise and accurate ground-based, in situ measurements from global monitoring networks. ${ }^{9,10}$ The location and frequency of these measurements are, however, very sparse on a global scale and even sparser at high latitudes where the thawing Arctic permafrost is of particular concern. Large quantities of organic carbon are stored in the Arctic permafrost and a warming climate can induce drastic changes in carbon emissions and a subsequent positive feedback mechanism can significantly accelerate climate change. ${ }^{11}$

Global measurements from satellites are available from passive optical sensors Atmospheric Infrared Sounder, ${ }^{12}$ Scanning Imaging Absorption Spectrometer for Atmospheric Chartography, ${ }^{13,14}$ Tropospheric Emission Spectrometer, ${ }^{15}$ Infrared Atmospheric Sounding Interferometer, ${ }^{16}$ and Greenhouse Gases Observing Satellite, ${ }^{17}$ but currently lack the required sensitivity to derive regional $\mathrm{CH}_{4}$ sources. Passive sensors measuring reflected sunlight are limited to sunlit areas of the planet and their sensitivity falls off at low sun angles, increasing cloud cover, aerosol scattering, and low surface reflectivity. Recent observations indicate that the thawing Arctic permafrost is active even during the cold season ${ }^{18}$ highlighting the need for continuous sampling at high latitudes even in the winter months.

The benefit of active sensing missions is that they provide global $\mathrm{CH}_{4}$ measurements where they are really needed: in the absence of sunlight (i.e., at night and at high latitudes in all seasons), in the presence of scattered or optically thin clouds and aerosols, over land and water surfaces, and with higher accuracy and precision than currently available. Active measurements using laser remote sensing technology will be a key step in obtaining measurements of $\mathrm{CH}_{4}$ from orbit with sufficient coverage, sampling, accuracy, and precision to address key science questions. The French Centre National d'Etudes Spatiales in collaboration with the German Aerospace Centre (DLR) are developing an active methane mission called Methane Remote Sensing Lidar Mission (MERLIN) scheduled for launch in 2021. ${ }^{19,20}$ The MERLIN mission targets an 8 to $36 \mathrm{ppbv}$ relative random error in the methane column abundance with a 50-km horizontal resolution.

At NASA Goddard Space Flight Center (GSFC), we have been developing an active, airborne lidar to measure atmospheric methane using integrated path differential absorption (IPDA) as a precursor to a space mission to measure $\mathrm{CH}_{4}$ from orbit.

\section{Instrument Description}

An IPDA lidar measures the absorption of laser pulses by a trace gas when tuned to a wavelength coincident with an absorption line. ${ }^{21-31}$ Using the instrument in a sounding (surface reflection) mode enables integrated column trace gas measurements from orbit with relatively modest laser power.

The GSFC IPDA lidar uses a tunable, narrow-linewidth light source, and a photon-sensitive detector coincident with a $\mathrm{CH}_{4}$ absorption at $1650.96 \mathrm{~nm}$. The $\mathrm{CH}_{4}$ spectrum at $1650.96 \mathrm{~nm}$ is well suited for active remote sensing. The $\mathrm{CH}_{4}$ line is mostly isolated from adjacent $\mathrm{CO}_{2}$ lines and there is very little water $\left(\mathrm{H}_{2} \mathrm{O}\right)$ vapor interference. The MELRIN line at $1645.55 \mathrm{~nm}$ is less suitable for our technique because it is interfered with by $\mathrm{H}_{2} \mathrm{O}$ vapor at $\sim 1645.47 \mathrm{~nm}$ and it is wider than our line ( $\sim 56$ versus $\sim 36 \mathrm{pm}$ ), an important consideration because it increases the tuning requirement for our laser transmitter. Figure 1 shows the two-way atmospheric transmittance spectrum around $1650.96 \mathrm{~nm}$ from a $400-\mathrm{km}$ orbit using the 2008 HITRAN database $^{32}$ and a US standard atmosphere.

Although in principle only two wavelengths ("on" and "off" the line) are needed to determine the transmittance through the atmospheric column, our technique uses multiple wavelengths to probe the absorption feature. Using multiple wavelengths can reduce errors that may affect the measurement precision,$^{33}$ measure the spectral shift of the line with changing atmospheric pressure, ${ }^{34}$ generate atmospheric backscatter profiles of the entire column, ${ }^{35}$ and enable retrievals of trace gas mixing ratios above and below the planetary boundary layer. ${ }^{36}$

An early version of our instrument ${ }^{25}$ flew in 2011. The major differences between the system in Ref. 25 and the new instrument are: (1) the detector: in 2011, we used a very low $(<1 \%)$ 


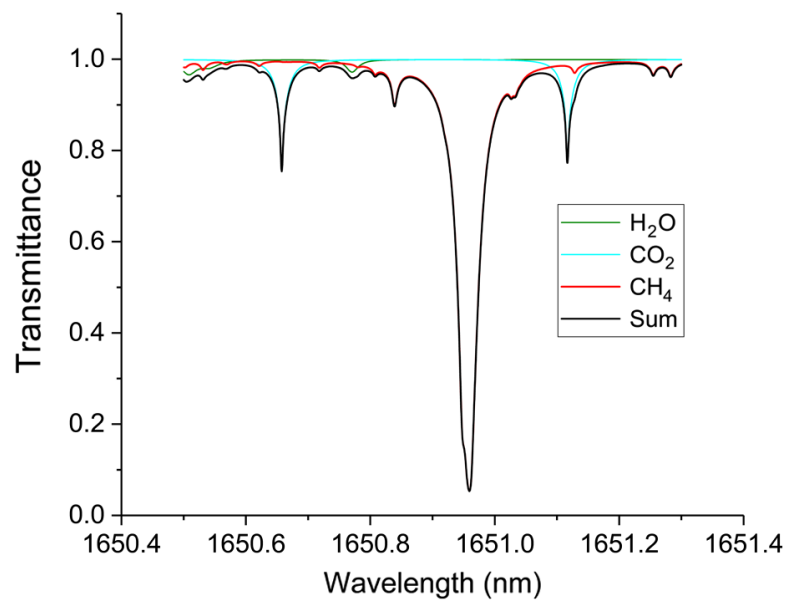

Fig. 1 Two-way atmospheric transmittance near $1650.96 \mathrm{~nm}$ from 400-km orbit using the 2008 HITRAN database and a US standard atmosphere. The $\mathrm{CH}_{4}$ line is mostly isolated from adjacent $\mathrm{CO}_{2}$ and $\mathrm{H}_{2} \mathrm{O}$ vapor lines.

quantum efficiency $(\mathrm{QE})$ photomultiplier tube with very limited dynamic range. The new instrument used an enhanced avalanche photodiode (e-ADP) with 90\% QE. (2) The type and energy of the transmitter(s): in 2011, we used a low-energy optical parametric amplifier (OPA) laser transmitter with pulse energy of $\sim 10 \mu \mathrm{J}$. The new airborne lidar used an OPA and an optical parametric oscillator (OPO) with pulse energies of $\sim 25$ and $\sim 250 \mu \mathrm{J}$, respectively. (3) The optomechanical layout and data acquisition system were completely redesigned and considerably improved. As a result, spurious effects such as etalon fringes were dramatically reduced, which improved the precision of the instrument.

Our new airborne IPDA lidar used two different laser transmitters. The first is an OPA and the second is an OPO. Only one laser transmitter is used at a time using a movable mirror to select the desired transmitter. A simplified block diagram of our lidar is shown in Fig. 2 and is based on our previous work with optical parametric generation. ${ }^{37}$

The OPA, used 20 wavelengths, but was simpler to implement than the OPO, because it did not require an optical resonator cavity, was easier to align and tune, and used only two seed lasers. However, it is extremely difficult to scale the OPA energy to the level needed for space and still maintain a narrow linewidth. Depending on the receiver size and other instrument parameters, we calculate that $\sim 600 \mu \mathrm{J}$ is needed to obtain a measurement with a $0.5 \%$ precision. The underlying reason for the wider linewidth is the large mismatch between the seed and pump energies, which makes it very difficult to amplify the seed with the desired spectral characteristics. If the seed laser power can be significantly scaled up and back-conversion can be suppressed, then it may be possible to achieve energies of $600 \mu \mathrm{J}$ out of the OPA with the desired spectral characteristics.

In the $\mathrm{OPO}$, narrow linewidth is achieved using an optical resonator cavity, which also enhances the energy of the nonlinear conversion. Our OPO uses five wavelengths and a $1.2 \mathrm{~mJ}$ GSFCbuilt solid-state pump laser with a triangular optical ring cavity. The OPO energy could be scaled to space $(\sim 600 \mu \mathrm{J})$ and maintain a narrow linewidth with a suitable higher energy pump laser and improved optical design. However, the OPO currently requires a separate seed laser and complex optical phase-lock loops for each wavelength used.

The first transmitter option (OPA) consists of a magnesium oxide-doped periodically poled lithium niobate (MgO:PPLN) crystal, which is pumped by a pulsed single-frequency $1064 \mathrm{~nm}$ laser and seeded by a continuous wave (CW) $1650.96 \mathrm{~nm}$ laser diode. The pump laser is a custom burst-mode $\mathrm{Yb}$ fiber laser from Fibertek Inc., based on a master oscillator power amplifier configuration. ${ }^{38}$ The pump laser was optimized for high peak power and generated $600 \mu \mathrm{J}$ in a burst pulse. Each burst pulse consists of 20 individual 3 ns pulses separated by $85 \mathrm{~ns}$ with the individual pulse energies in the burst varying from 2 to $10 \mu \mathrm{J}$. An example of the OPA burst pulse is shown in Fig. 3. 
Riris et al.: Methane optical density measurements with an integrated path differential absorption...

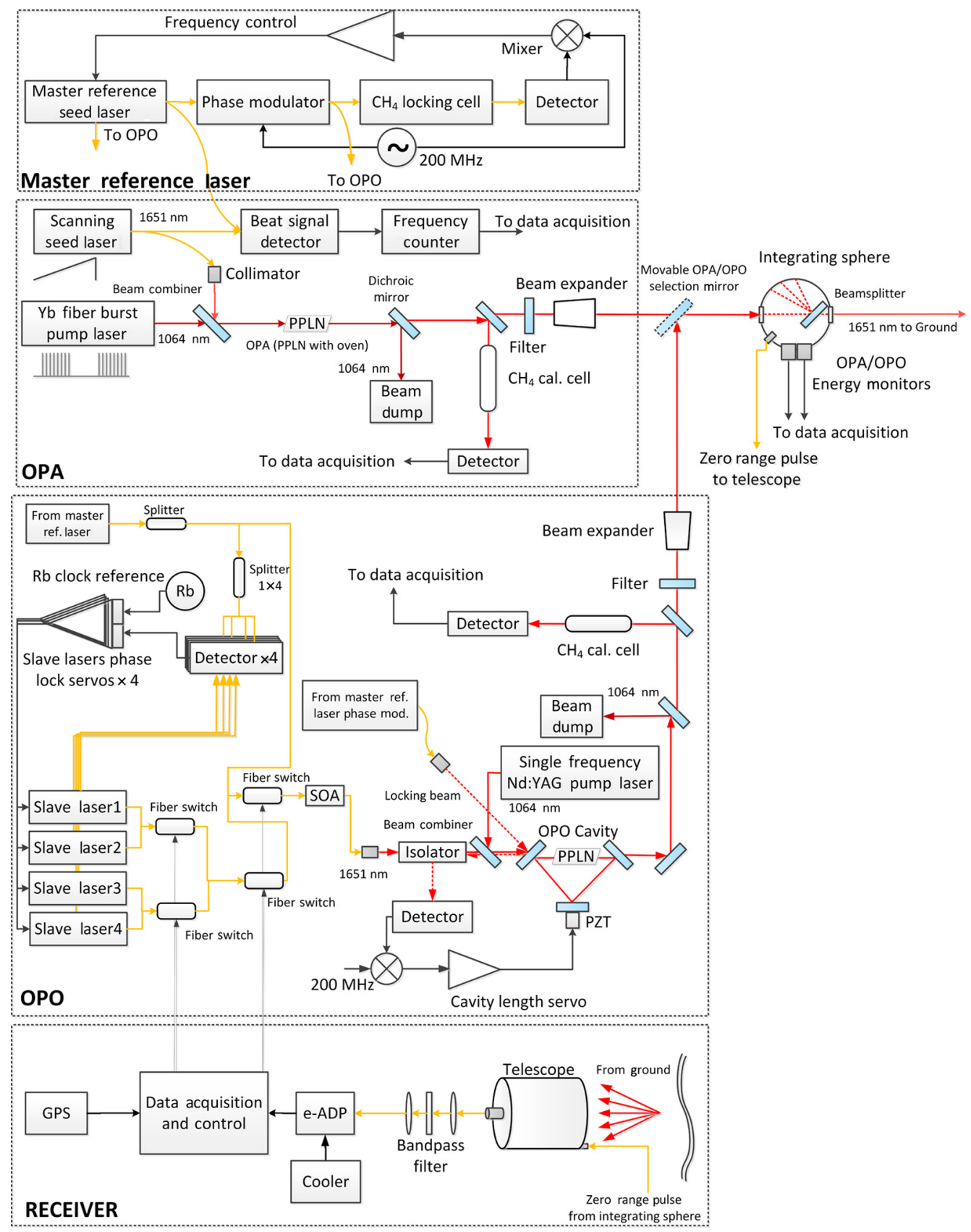

Fig. 2 Simplified functional block diagram of our IPDA lidar. The lidar can use one of two different laser transmitters using a movable selection mirror: an OPA or an OPO. The transmitters use DFB diode lasers for seed lasers but different pump lasers. Only one laser transmitter is operating during flight.

The OPA output varies nonlinearly with the peak power of the pump so the variation in the individual pump pulses resulted in very low conversion in the OPA of the low-energy pulses. The linewidth of the OPA was $\sim 500 \mathrm{MHz}$. The pump laser was delivered with a bare, large mode area fiber output that optimized the power output but was not suitable for flight. Prior to our flights, we connectorized the output and the burst pulse energy was reduced to $350 \mu \mathrm{J}$ per burst pulse.

Two distributed-feedback (DFB) CW diode lasers, a master reference and a scanning seed, from NEL America (NLK1U5FAAA), are used in the OPA. The wavelength of the master reference laser is locked on the absorption peak at $\sim 1650.96 \mathrm{~nm}$ using a $16.5-\mathrm{cm}$ cell containing $\sim 40$ mbar of $\mathrm{CH}_{4}$. The locking technique is the same for both the OPA and OPO, and is described by Numata et al. ${ }^{39,40}$ It is based on the technique used by Pound-Drever-Hall ${ }^{41}$ and 


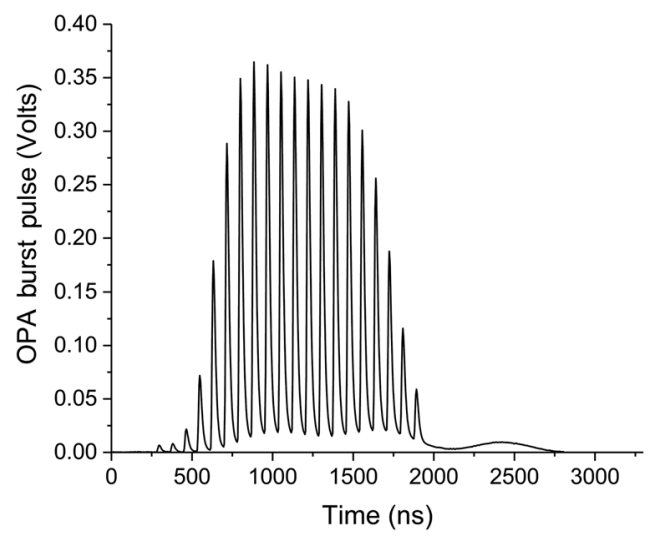

Fig. 3 Example of temporal shape of the OPA burst pulse from the energy monitor detector showing individual pulses within the burst pulse.

is similar to the technique used by Fix et al. ${ }^{42}$ We estimate that the long-term drift of the master laser frequency is $\sim 2 \mathrm{MHz}$, based on our experience with similar DFB seed lasers for $\mathrm{CO}_{2}$.

The scanning seed laser is tuned over the $\mathrm{CH}_{4}$ line by rapidly scanning the laser current. The beat signal between the master reference laser and the scanning seed laser is measured by a frequency counter and recorded by the data acquisition system. The frequency of the beat signal is converted into the OPA wavelengths in postprocessing.

The scanning seed and pump laser beams are combined with a beam combiner and focused through the PPLN crystal. The temperature of the PPLN crystal can be tuned to optimize the phase matching at the seed wavelength. The unconverted pump beam at $1064 \mathrm{~nm}$ is separated from the signal beam at $1650.96 \mathrm{~nm}$ using a dichroic mirror and directed into a beam dump. A small part of the OPA beam at $1650.96 \mathrm{~nm}$ is also directed through an $8-\mathrm{cm}$ reference cell containing $\sim 170$ mbar of $\mathrm{CH}_{4}$ for calibration purposes and a blocking filter prevents any remaining $1064 \mathrm{~nm}$ radiation from existing the aircraft. The main OPA output beam is directed through a beam expander to reduce its divergence. The final output energy of the OPA transmitter exiting the aircraft was $\sim 25 \mu \mathrm{J}$ per burst pulse and 20 wavelengths were used in each wavelength scan to sample the $\mathrm{CH}_{4}$ lineshape.

The second transmitter (OPO) consists of another temperature-controlled PPLN crystal inside a three-mirror cavity. The temperature of the PPLN crystal can be temperature-tuned to optimize the phase matching at the seed wavelength. The OPO is pumped by a pulsed single-frequency $1064 \mathrm{~nm}$ Nd:YAG laser and seeded by five CW DFB lasers at $\sim 1650.96 \mathrm{~nm}$.

The pump laser of the OPO is a custom-made GSFC single-frequency Nd:YAG laser with a $\sim 60 \mathrm{~ns}$ pulse width and maximum energy of $1.2 \mathrm{~mJ}$ per pulse at a $5 \mathrm{kHz}$ repetition rate.

The same master reference seed laser used in the OPA is used for the OPO. Part of the phasemodulated master reference beam (labeled "locking beam" in Fig. 2) is used to lock the OPO cavity using a cavity length-control servo and a piezoelectric transducer. Four additional slave DFB diode lasers are offset-locked to the master reference laser by an integral number of the OPO cavity free-spectral range using the beat signal from four detectors and four optical phase locked loop servos and a Rubidium frequency reference. Thus, the OPO samples the $\mathrm{CH}_{4}$ absorption at five wavelengths (one master and four slave). The wavelengths are selected by switching fast $\left(\right.$ NanoSpeed $\left.{ }^{\mathrm{TM}}\right) 1 \times 2$ fiber optic switches made by Agiltron.

After exiting the OPO cavity, the unconverted pump beam at $1064 \mathrm{~nm}$ is separated from the signal beam at $1650.96 \mathrm{~nm}$ using a dichroic mirror and directed into a beam dump. After the dichroic mirror, a small part of the OPA beam at $1650.96 \mathrm{~nm}$ is directed through a $5-\mathrm{cm}^{\mathrm{CH}_{4}}$ reference cell containing $\sim 260$ mbar of $\mathrm{CH}_{4}$ for calibration purposes and a blocking filter prevents any remaining $1064 \mathrm{~nm}$ radiation from existing the aircraft. The main OPO output beam is directed through a beam expander to reduce its divergence. The maximum output energy of the OPA transmitter exiting the aircraft was $\sim 250 \mu \mathrm{J}$ per pulse. The measured linewidth of the OPO was $<300 \mathrm{MHz}$, but the measurement was limited by the resolution of the FebryPerot etalon we used. ${ }^{39}$ 
Riris et al.: Methane optical density measurements with an integrated path differential absorption...

The divergence for both laser transmitters was $\sim 150 \mu \mathrm{rad}$. Prior to exiting the aircraft through the nadir port, a wedged beam splitter sends a small portion of the outgoing beams $(\sim 4 \%)$ to an $8.9-\mathrm{cm}$ diameter integrating sphere with two InGaAs detectors attached to one of its ports (one for the OPA and one for the OPO). The detectors measure the outgoing energy monitor pulses for the OPO or OPA and are digitized by the data acquisition system. The energy monitor pulses are used to normalize the reflected pulses from the ground every $1 / 16 \mathrm{~s}$ in postprocessing. In addition to the energy monitors, a multimode $200-\mu \mathrm{m}$ core fiber is also connected to a port of the integrating sphere and collects a small fraction of the outgoing laser energy. The multimode fiber output is collimated and fed back into the receiver telescope and focused on our sensitive detector to provide a zero-range pulse (or "start pulse") for our ranging algorithm. The time of flight (TOF) from the zero-range pulse to the reflected pulses from the ground is used to determine the IPDA lidar range.

The laser pulses reflected from the ground are collected by a commercial $20-\mathrm{cm}$ diameter receiver telescope (Vixen VC200L) with an effective focal length of $2 \mathrm{~m}$ and are coupled into an antireflection-coated $600-\mu \mathrm{m}$ core multimode fiber. The receiver field of view (FOV) was $300 \mu \mathrm{rad}$. The receiver fiber output is collimated by a lens and directed through a $0.8 \mathrm{~nm}$ [full width at half maximum (FWHM)] bandpass filter, and then focused onto an HgCdTe-e-ADP by DRS Technologies. ${ }^{43-45}$ The detector is a $4-\times 4$-pixel array, with the pixel pitch being $80 \mu \mathrm{m}$ with no gaps between pixels. The detector is operated at $80 \mathrm{~K}$ and its electrical bandwidth is $\sim 7 \mathrm{MHz}$.

The signals from the frequency counter, reference cell (OPA or OPO), the energy monitor (OPA or OPO), the zero-range pulse, and ground return pulses are digitized by a National Instruments ${ }^{\mathcal{C}}$ PXI-based data acquisition system containing a FlexRIO FPGA module, a

Table 1 Instrument parameters.

\begin{tabular}{|c|c|c|}
\hline Parameter & OPA & OPO \\
\hline Center wavelength & $1650.958 \mathrm{~nm}$ & $1650.958 \mathrm{~nm}$ \\
\hline Number of wavelengths used & 20 & 5 \\
\hline Transmitter energy/pulse & $\sim 25$ to $30 \mu \mathrm{J}$ & $\sim 250 \mu \mathrm{J}$ \\
\hline Transmitter pulse rate & $10 \mathrm{kHz}$ & $5 \mathrm{kHz}$ \\
\hline Transmitter divergence & $\sim 150 \mu \mathrm{rad}$ & $\sim 150 \mu \mathrm{rad}$ \\
\hline Spectral linewidth & $\sim 500 \mathrm{MHz}$ & $<300 \mathrm{MHz}^{\mathrm{a}}$ \\
\hline Number of seed lasers used & 2 & 5 \\
\hline Pump laser & Burst mode Yb Fiber & Single pulse Nd:YAG \\
\hline Pump laser energy & $350 \mu \mathrm{J}$ & $1.2 \mathrm{~mJ}$ \\
\hline Receiver diameter & $20 \mathrm{~cm}$ & $20 \mathrm{~cm}$ \\
\hline Receiver field of view & $300 \mu \mathrm{rad}$ & $300 \mu \mathrm{rad}$ \\
\hline Receiver bandpass & $0.8 \mathrm{~nm}(\mathrm{FWHM})$ & $0.8 \mathrm{~nm}(\mathrm{FWHM})$ \\
\hline Detector & $4 \times 4 \mathrm{HgCdTe}$ e-ADP & $4 \times 4 \mathrm{HgCdTe}$ e-ADP \\
\hline Detector pixel pitch & $80 \mu \mathrm{m}$ & $80 \mu \mathrm{m}$ \\
\hline Detector QE & $\sim 90 \%$ & $\sim 90 \%$ \\
\hline Detector temperature & $80 \mathrm{~K}$ & $80 \mathrm{~K}$ \\
\hline Detector bandwidth & $7 \mathrm{MHz}$ & $7 \mathrm{MHz}$ \\
\hline Averaging time & $1 / 16 s$ & $1 / 16 s$ \\
\hline
\end{tabular}

aLinewidth measurement limited by the resolution of the scanning Febry-Perot etalon used. 
FlexRIO digitizer adapter module, a timing and synchronization module, and a global positioning system (GPS) module. All signals are averaged every $1 / 16 \mathrm{~s}$ and the files are time stamped by the GPS time. Additional averaging can be performed in postprocessing. The major parameters of the airborne IPDA lidar are summarized in Table 1.

\section{Airborne Demonstration Results}

\subsection{Flights}

In late September 2015, the instrument was installed on the NASA DC-8 airborne laboratory, based at Armstrong Flight Research Center Science Aircraft Integration Facility in Palmdale, California. The transceiver structure supported two small, vibration isolation, optical benches for the OPO and OPA, the receiver telescope, and the transmit optics components. A vibration isolation mechanism for the entire structure minimized the impact of aircraft vibrations. The overall transceiver dimensions were $\sim 0.9 \times 2.0 \times 0.8 \mathrm{~m}^{3}$ and the total weight was $363 \mathrm{~kg}$ (Fig. 4). Two aircraft racks on either side of the transceiver structure held ancillary instrumentation needed for the operation of the instrument (data acquisition and control computers, detector, seed lasers, electronics, chillers for the pump lasers, etc.).

A Picarro in situ analyzer (Picarro G1301-m) measuring methane, carbon dioxide, and water vapor using wavelength-scanned cavity ring down spectroscopy was also installed at a different location in the aircraft to provide in situ $\mathrm{CH}_{4}$ reference measurements.

Three flights in the western United States were carried out in late September to early October 2015. Flight planning was constrained by the limited number of flight hours available, the inclement weather, and aircraft maintenance issues. Each flight lasted about $4 \mathrm{~h}$ and included several segments at increasing altitudes from 2 to $13 \mathrm{~km}$ over varying topography, ground reflectivity (including ocean), and atmospheric conditions. In addition, a spiral descent from $\sim 13 \mathrm{~km}$ to near the surface ( $\sim 30$ to $300 \mathrm{~m}$ depending on Federal Aviation Administration flight clearances) was included in the flight plan in order to sample the localized vertical profile of the $\mathrm{CH}_{4}$ mixing ratio and associated meteorological parameters (pressure, temperature, humidity, etc.) using the Picarro in situ sensor and the aircraft's data acquisition system. The IPDA lidar

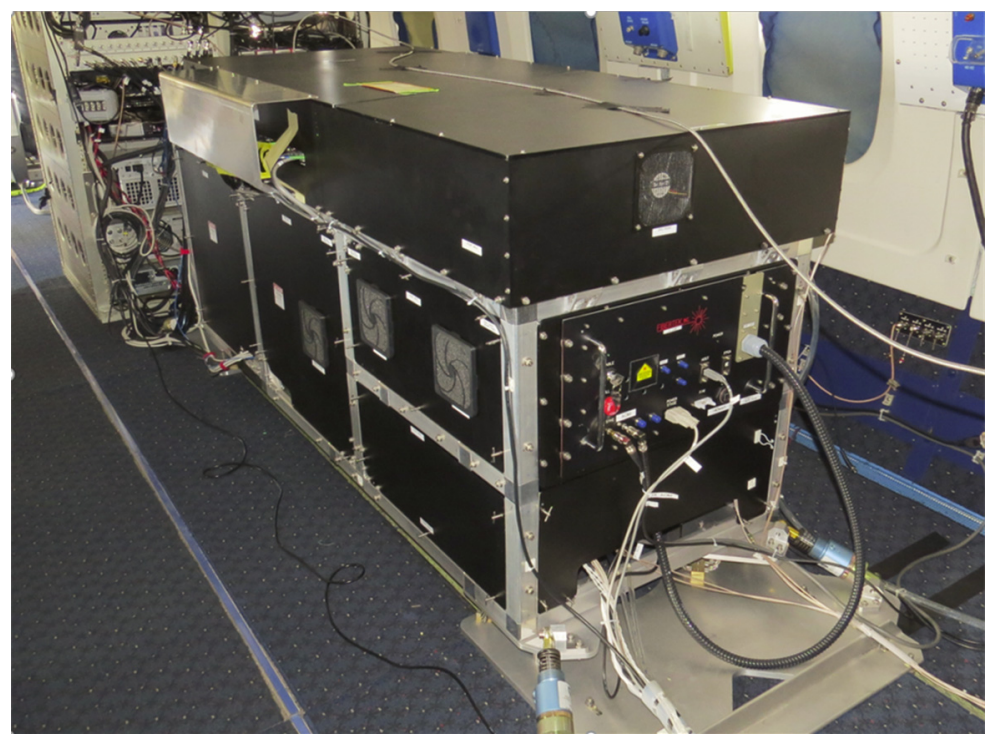

Fig. 4 The GSFC IPDA lidar installed on the NASA DC-8 airborne laboratory, in Palmdale, California. The transceiver structure supported two optical benches for the OPO and OPA, the receiver telescope, and the transmit optics components. The overall transceiver dimensions were $\sim 0.9 \times 2.0 \times 0.8 \mathrm{~m}^{3}$ and the total weight was $363 \mathrm{~kg}$. Two instruments racks on either side of the transceiver contained the control and data acquisition electronics. 


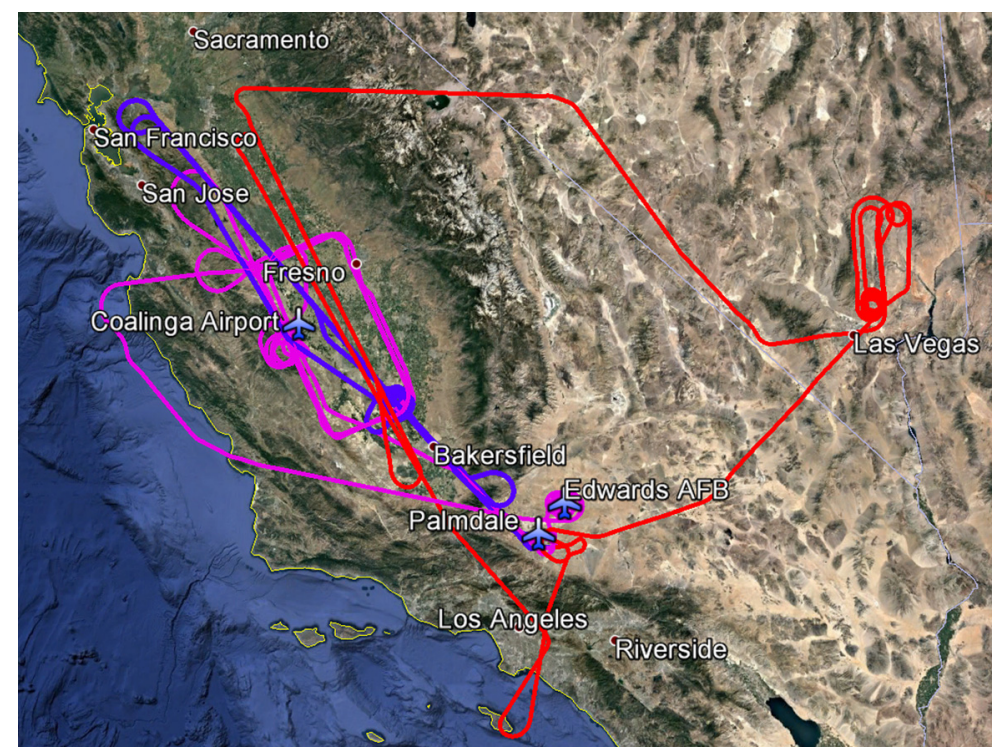

Fig. 5 Fight tracks for the 2015 flights. Flight 1 (blue), flight 2 (red), and flight 3 (magenta).

was always turned off below $1 \mathrm{~km}$ above ground level (AGL) to comply with strict laser safety requirements.

Figure 5 summarizes our flight paths in the western US. The flight tracks and locations were chosen to minimize the transit flight time and targeted areas of potential $\mathrm{CH}_{4}$ emission sources.

For the first two flights, we used the OPA transmitter and for the third flight, we used the OPO.

The first flight was mostly over the Central (San Joaquin) Valley of California. We flew on a general south-north track, at three different altitudes at $\sim 3.1,5.9$ to 6.0 , and $12.7 \mathrm{~km}$. A large portion of the flight was in and over a dense cloud cover and the spiral descent originally scheduled over Coalinga airport, California, was moved to $440-\mathrm{km}$ north of Bakersfield, California, due to the weather conditions. The Coalinga airport was originally chosen due to its proximity to a large feedlot.

The second flight targeted a large landfill $\sim 30-\mathrm{km}$ northeast of Las Vegas, Nevada. After an initial pass at $\sim 10 \mathrm{~km}$ and a subsequent spiral descent and low pass over the landfill at $\sim 300-\mathrm{m}$ AGL, two more flight segments were flown at 3.2 and $6.4 \mathrm{~km}$. Then we transited over to the Central Valley, California where we did two high-altitude north-south flight segments at 12.7 and $13.1 \mathrm{~km}$. Part of the Central Valley was completely covered by a dense cloud cover during our flight.

The third flight was again over the Central Valley of California mostly due to adverse weather conditions and flight restrictions at other candidate sites. We flew on a $\sim 75 \times 160 \mathrm{~km}^{2}$ rectangular path centered on the Central Valley at three different altitudes: $3.1,6.3$, and $12.7 \mathrm{~km}$. A spiral descent and low pass ( $\sim 30 \mathrm{~m}$ AGL) was performed over Coalinga airport. Following the high-altitude segment at $12.7 \mathrm{~km}$, we flew over the Pacific Ocean and performed another spiral descent over Edwards Air Force Base, California, prior to landing in Palmdale.

The flight altitude profiles (GPS altitude and IPDA lidar range versus time) are shown in Fig. 6.

\subsection{Retrievals}

Our retrieval algorithm uses a least squares fit to minimize the root mean squared error between the IPDA lidar measurements and the model prediction and is similar to the approach used by Abshire et al. ${ }^{46}$ in their $\mathrm{CO}_{2}$ retrievals. The averaging time for the data acquisition system is $1 / 16 \mathrm{~s}$, but the data are further averaged in postprocessing in 1-s intervals. First, the range (path length) from the aircraft to the surface is determined from the laser pulse TOF by correlating the first return pulse with the zero range pulse and measuring the time delay of the correlation 


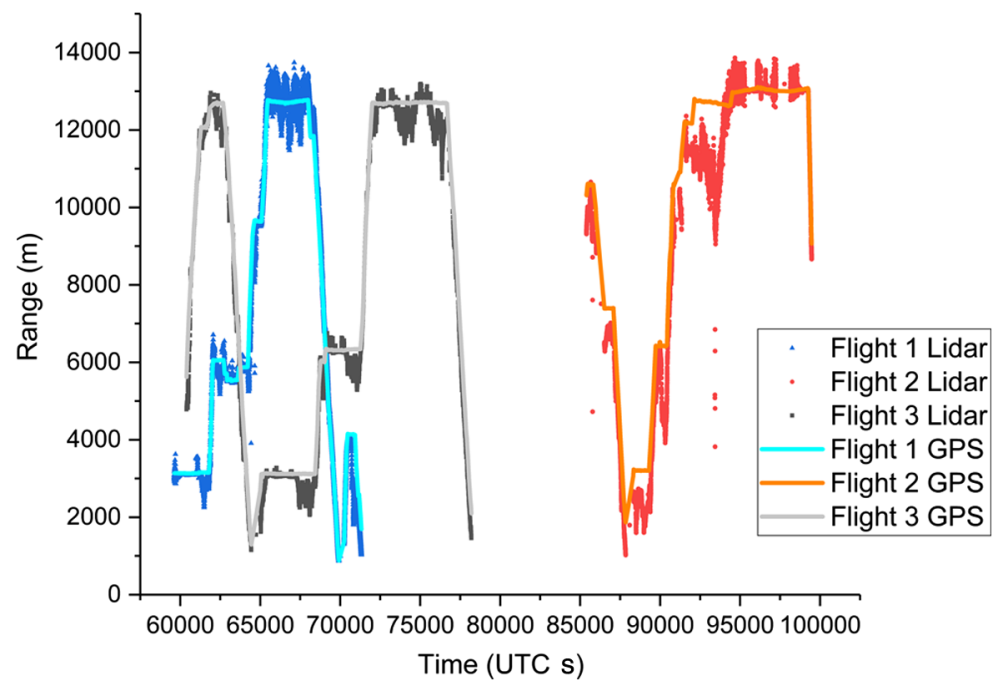

Fig. 6 Flight altitude (range) in meters versus time in coordinated universal time (UTC) seconds since midnight as measured by the GPS receiver and our IPDA lidar for all three flights. The differences between the GPS and the IPDA lidar range are due to topography. The GPS measures the altitude above the mean sea level (or reference ellipsoid), but the IPDA lidar range is the altitude (range) above ground, which includes the topography.

peak, following the cross-correlation approach by Amediek et al. ${ }^{47}$ The aircraft is equipped with a GPS antenna and a radar altimeter and we compare our lidar range with the radar range to ensure that only valid ground return pulses are used in the retrievals. If only cloud returns are present, the data are not used in the analysis. However, there were many occasions we had multiple returns from cumulus and cirrus clouds, and the ground. Segments that did not contain enough valid ground returns due to the presence of clouds or other instrument issues were excluded from the analysis. Generally, when fewer than $50 \%$ ground returns are present over a 1-s averaging period the data were not used. The algorithm then estimates the column average of $\mathrm{CH}_{4}$ transmittance of the atmospheric column by fitting the integrated pulse returns from the surface at each wavelength, after normalization by the transmitted pulse energy, the filter transmission, and other instrument calibrations. The algorithm compares the experimental with the theoretically calculated transmittance values and adjusts the fit parameters, including the mixing ratio, to minimize the fit error. The theoretical calculations used a Voigt lineshape, the lineshape parameters from the HITRAN 2008 database, and line-by-line radiative transfer calculations. ${ }^{48}$ The impact of more complicated lineshape functions and line mixing was not included in the calculations. However, recent spectroscopic measurements by Delahaye et $\mathrm{al}^{49}$ for the MERLIN line at $1645.55 \mathrm{~nm}$ suggest that differences of $1.5 \%$ up to $5 \%$ in the lineshape may arise if these effects are not taken into account. Figure 7 shows a theoretical $\mathrm{CH}_{4}$ lineshape from a 400-km altitude orbit with a US standard atmosphere, and a comparison of the corresponding wavelength sampling by the OPA and OPO (20 versus 5 wavelengths).

The meteorological data for the vertical profile of the atmosphere are obtained from the spiral descents, the Goddard Modeling and Assimilation Office, Modern Era Retrospective Analysis for Research and Applications (MERRA), ${ }^{50}$ and the Goddard Earth Observing System Model, Version $5^{51}$ with a sampling-interpolating interval of 1 second. The true $\mathrm{CH}_{4}$ mixing ratio profile over the entire flight path is of course, unknown. For simplicity, in our analysis the $\mathrm{CH}_{4}$ mixing ratio used in the radiative transfer calculations was set at a constant $1900 \mathrm{ppb}$. Although this value is clearly not an accurate estimate of the true mixing ratio for an entire flight, it is not very different from the column average values obtained by the in situ spectrometer during our spirals and it provided a reasonable basis for estimating the precision, but not necessarily the accuracy, of the IPDA lidar. In order to better assess the accuracy of an IPDA lidar, more frequent spirals and/or data from radiosondes are needed to infer the mixing ratio profile over a flight path.

Figure 8 shows the time series data of the in situ $\mathrm{CH}_{4}$ mixing ratio measured by the Picarro, the theoretical $\mathrm{CH}_{4}$ mixing ratio, set at $1900 \mathrm{ppb}$, and the $\mathrm{CH}_{4}$ mixing ratio values obtained from 


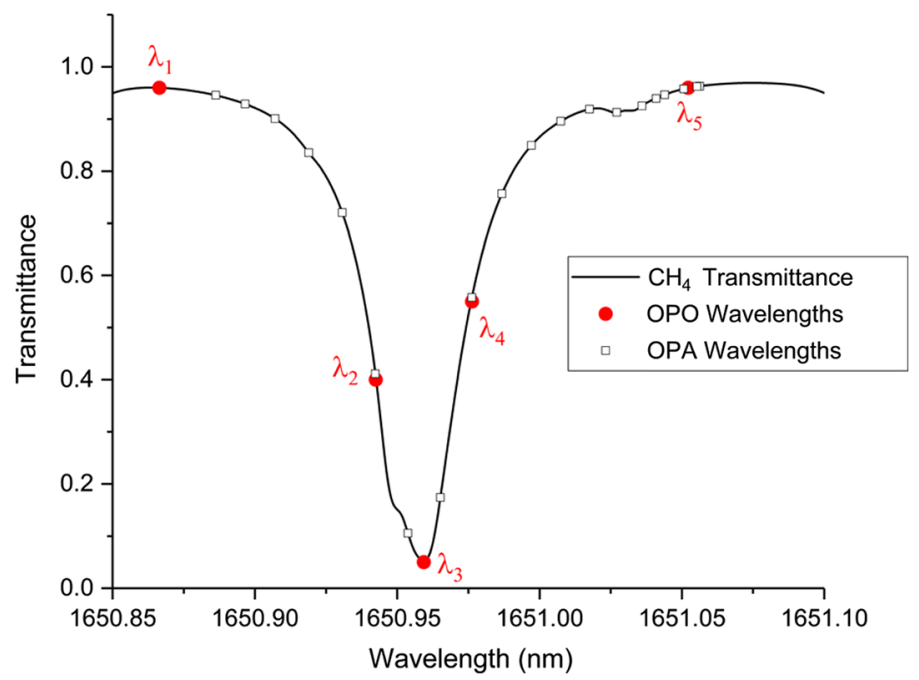

Fig. 7 Theoretical $\mathrm{CH}_{4}$ transmittance from a 400-km altitude with a US standard atmosphere and a comparison of the approximate wavelength sampling by the OPA (black open squares, 20 wavelengths) and OPO (red solid circles, five wavelengths). (For clarity, the OPO wavelengths are labeled $\lambda_{1}, \lambda_{2}, \lambda_{3}, \lambda_{4}$, and $\lambda_{5}$ ).

our retrieval algorithm for flight 1 . There are obvious differences between the instrument retrievals and those from the Picarro. That is to be expected since the Picarro is an in situ measurement and the lidar measures the column average.

There were multiple outliers in our retrievals that were filtered out. These were mainly due to two factors: instrument adjustments and optically thick clouds. Due to aircraft vibrations and changes in the cabin temperature and pressure, the OPA transmitter needed alignment adjustments during flight to reoptimize its power. In addition, the wavelength locking circuitry and instrumentation that locked and reported the wavelength of each laser pulse, by measuring the frequency of the beat note between the reference laser and the scanning seed laser wavelengths, would occasionally report erroneous values. The average wavelength values are used if the reported wavelength value did not deviate more than $\pm 20 \mathrm{pm}$ from the moving average wavelength value. Finally, a significant part of the flight was over broken, optically thick clouds.

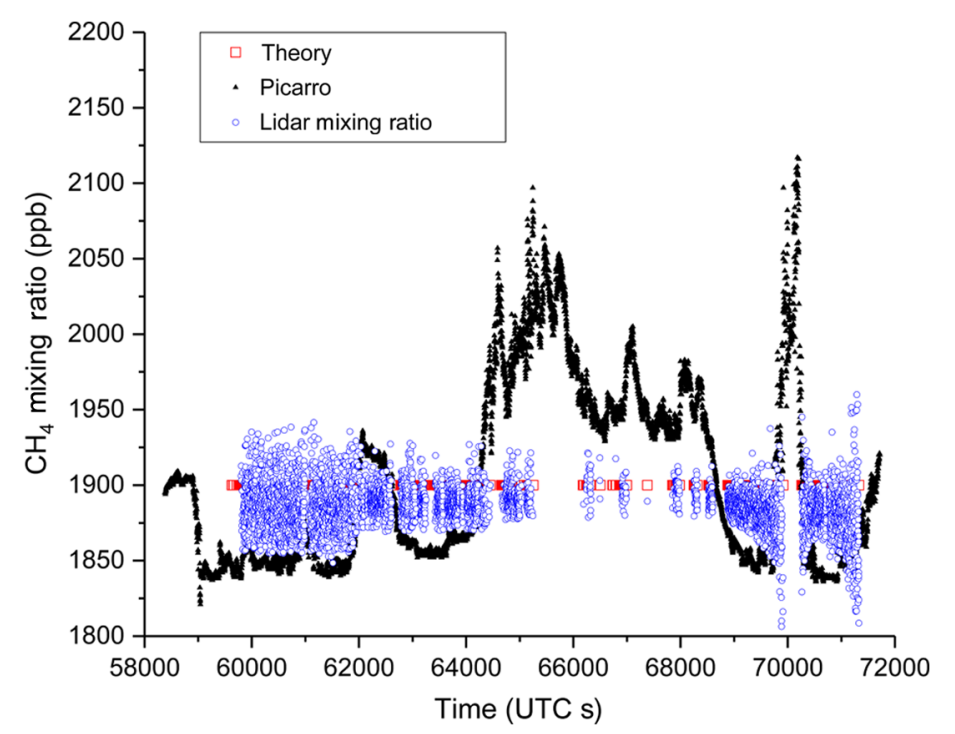

Fig. 8 Time series data for flight 1 showing the in situ $\mathrm{CH}_{4}$ mixing ratio as measured by the Picarro, the theoretical $\mathrm{CH}_{4}$ mixing ratio (set at $1900 \mathrm{ppbv}$ ), and the $\mathrm{CH}_{4}$ mixing ratio values by our retrieval algorithm. Outliers due to instrument adjustments and clouds were filtered out. 
When all the outliers due to broken clouds and instrument adjustments were filtered out, the agreement between the theoretical $\mathrm{CH}_{4}$ mixing ratio, set at $1900 \mathrm{ppb}$, and the retrieved $\mathrm{CH}_{4}$ mixing ratio values was very good, and the standard deviation of the retrieved $\mathrm{CH}_{4}$ mixing ratio was $14.9 \mathrm{ppb}$ or $\sim 0.8 \%$ (14.9/1900 ppb). Assuming the column average $\mathrm{CH}_{4}$ mixing ratio did not vary significantly, this value represents a reasonable estimate of the measurement precision of our IPDA lidar. Another good way to assess the IPDA lidar performance is to plot the experimentally retrieved differential optical depth (DOD) versus the theoretical value. The theoretical and experimental DOD values are determined by the difference in optical depth (OD) between the on wavelength interpolated at the wavelength closest to the peak $(\sim 1650.965 \mathrm{~nm})$ and the average value of the OD at the off wavelengths to the left and right of the absorption ( $\sim 1650.887$ and $\sim 1651.056 \mathrm{~nm}$, respectively). After removing all the outliers due to laser power adjustments, erroneous wavelength values and broken clouds, the DOD lidar versus DOD theory linear fit (Fig. 9), had a slope of 0.98 and an offset of -0.007 . The $R^{2}$ value was 0.994 .

Figure 10 shows the time series data for flight 2: the in situ $\mathrm{CH}_{4}$ mixing ratio as measured by the Picarro, the theoretical $\mathrm{CH}_{4}$ mixing ratio (set at $1900 \mathrm{ppbv}$ ), and the IPDA lidar $\mathrm{CH}_{4}$ mixing ratio values. Again, outliers due to instrument adjustments and the presence of optically thick clouds were filtered out. The standard deviation of the retrieved $\mathrm{CH}_{4}$ mixing ratio was $13.4 \mathrm{ppb}$ or $\sim 0.7 \%$ (13.4/1900 ppb). The DOD lidar versus DOD theory linear fit for flight 2 had a slope of 0.998 and an offset of -0.007 (Fig. 11). The $R^{2}$ value was 0.990 . These values are consistent with flight 1 results indicating that when the instrument is operating properly (i.e., no adjustments are being made and no cloud interferences) it is capable of measuring $\mathrm{CH}_{4}$ mixing ratios with a $0.7 \%$ to $0.8 \%$ precision. Obviously, the definition of the instrument "operating properly" is subjective and in our case, it excluded sections of the flights where the instrument needed adjustments. However, the current results provide "proof-of-principle" evidence that a multiwavelength IPDA lidar with an OPA can provide high enough precision for meaningful science measurements from an airborne platform over a varying topography and altitudes from 2 to $13 \mathrm{~km}$.

The last flight (flight 3 ) used the OPO as the laser transmitter. As shown in Table 1, the OPO used only five wavelengths versus 20 for the OPA. Fewer wavelengths mean that the lineshape is under-sampled and thus, it is more difficult to identify and remove any baseline slope and/or other artifacts in the data. The OPO transmitter also required adjustments during flight. In addition, the high OPO energy $(\sim 250 \mu \mathrm{J})$ presented additional challenges. It saturated our detector especially at lower altitudes. Our initial plan to attenuate the received energy by restricting the receiver aperture size with a variable iris did not work for the flight configuration on the DC-8, even though we tested the idea successfully in the laboratory. The hardware that was used to restrict the receiver aperture size produced a large near-field backscatter when installed in the aircraft saturating and turning off the DRS detector. As a result, it could not be used for flight and

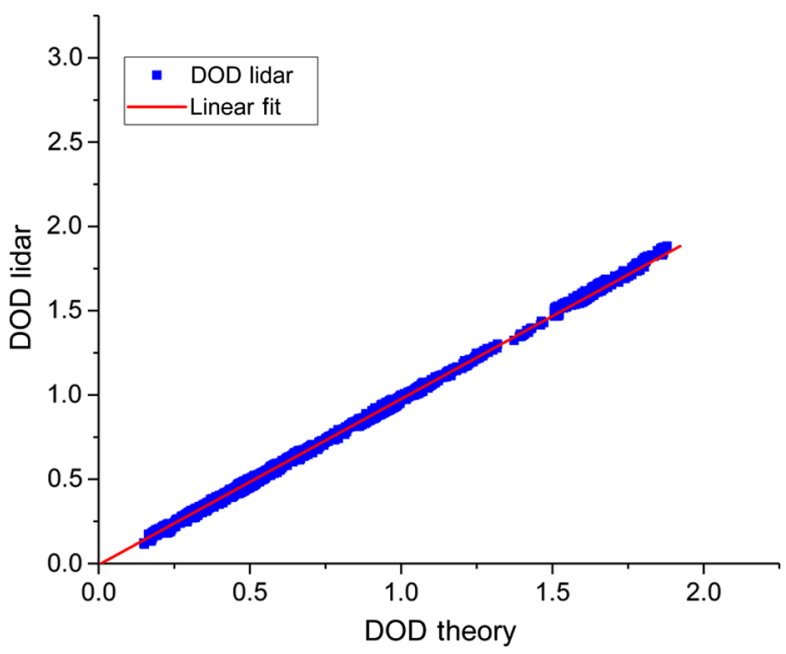

Fig. 9 Lidar DOD versus theoretical DOD for flight 1. The linear fit (without the outliers) had a slope of 0.98 and an offset of -0.007 and $R^{2}$ value was 0.994 . 


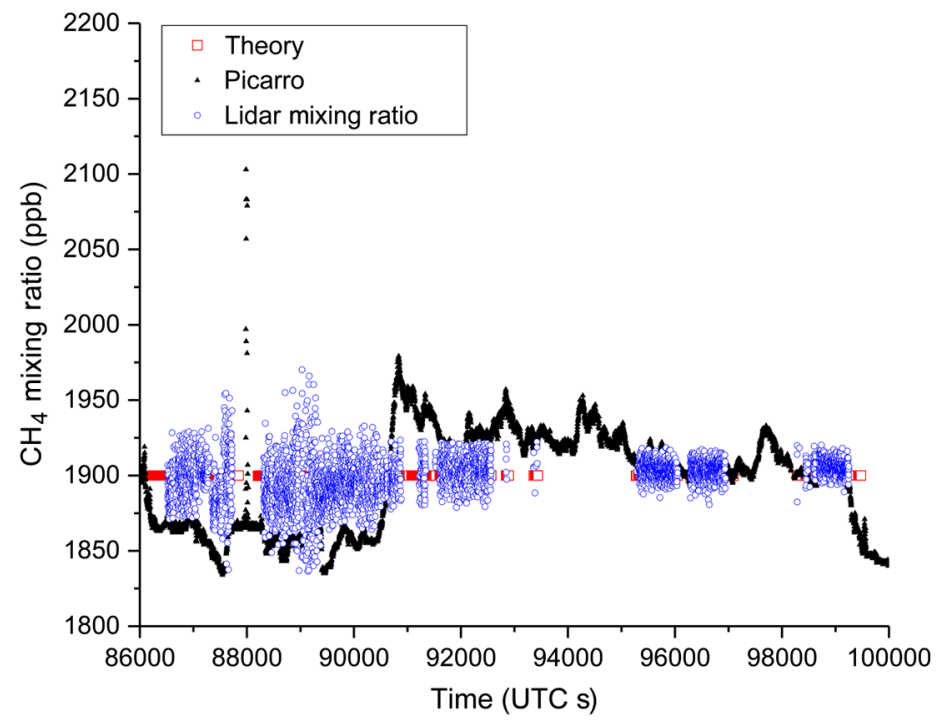

Fig. 10 Time series for flight 2 data showing the in situ $\mathrm{CH}_{4}$ mixing ratio as measured by the Picarro, the theoretical $\mathrm{CH}_{4}$ mixing ratio (set at $1900 \mathrm{ppbv}$ ), and the $\mathrm{CH}_{4}$ mixing ratio values by our retrieval algorithm. Outliers due to instrument adjustments and clouds were filtered out.

thus, the OPO energy was too high for the detector, especially for the low-altitude flight segment and over highly reflective surfaces. The detector gain had to be turned down to its minimum value for part of the flight where the detector was presumed to be nonlinear. Our initial analysis showed a large discrepancy between the theoretical and experimental DOD values. More importantly, we expected the discrepancy to be worse for the lower altitude segment of the flight, where the detector was saturated and the gain was turned down to a minimum. Contrary to our initial expectations, the DOD discrepancy was worse for the higher altitude segment of the flight, where the detector was not saturated and operating in a linear regime. Repeated postflight calibrations of the DRS detector in the laboratory failed to uncover any significant detector nonlinearities within the digitizer dynamic range (1.23 V peak-peak) that could account for the discrepancy we observed. For a given detector gain (bias) above threshold, the detector is linear over at least two orders of magnitude and even when the detector gain is set to its minimum value the results were repeatable and could be calibrated. Another possible problem we uncovered in our post flight calibration was wavelength locking. Wavelength $1\left(\lambda_{1}\right)$ was initially reporting a "lock" status even though it was not always properly locked on the correct wavelength.

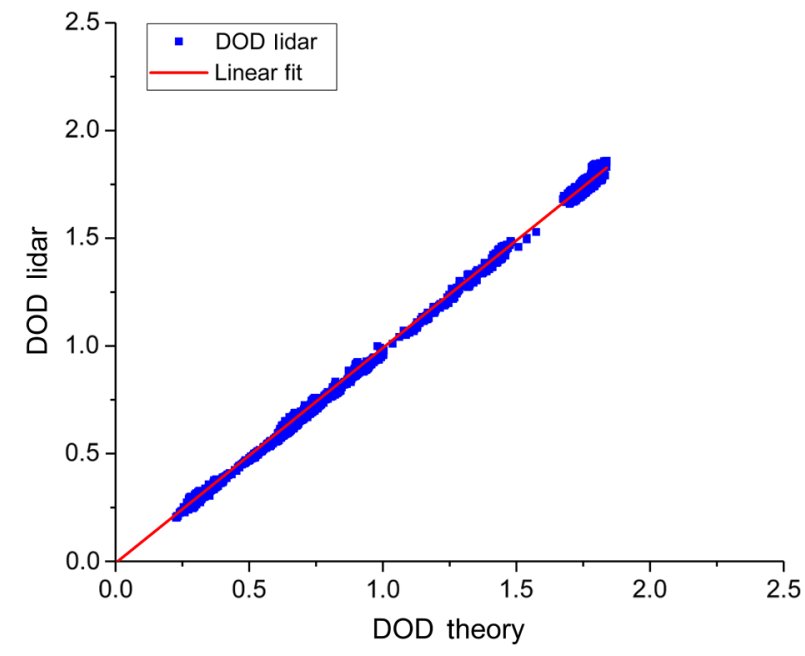

Fig. 11 Lidar DOD versus theoretical DOD for flight 2. The linear fit (without the outliers) had a slope of 0.998 and an offset of -0.007 and $R^{2}$ value was 0.990 . 
The problem was corrected quickly during flight (shortly after the first spiral around 64,000 s UTC), but the data prior to the correction had to be discarded. We hypothesized that the other wavelengths might have also experienced the same issue later in the flight. Several postflight calibrations in the laboratory with a high-resolution wavemeter showed that the wavelength locking circuitry was operating properly and the circuitry was reporting the wavelength values correctly. A detailed analysis of the OPO reference cell indicated that the discrepancy was not due to the detector or the wavelength locking. The discrepancy was traced to the fast fiber optic switches used to switch between the five OPO wavelengths. The switches have a small amount of crosstalk and although the crosstalk was initially measured to be relatively small, $(\sim 1 \%$ to $1.5 \%$ ), the effect on the signal can be significant especially at higher altitudes. Because of the crosstalk, the total signal received at each wavelength has contributions from all five wavelengths. Wavelengths 1 and $5\left(\lambda_{1}\right.$ and $\left.\lambda_{5}\right)$ are "off line" and are not absorbed. Wavelengths 2,3 , and $4\left(\lambda_{2}, \lambda_{3}, \lambda_{4}\right)$, however, are absorbed and the amount of absorption increases with altitude. As the altitude (absorption) increases the "on line" wavelengths $\left(\lambda_{2}, \lambda_{3}, \lambda_{4}\right)$ signals, have increasing contributions from the off line wavelengths $\left(\lambda_{1}\right.$ and $\left.\lambda_{5}\right)$. Thus, a correction factor is needed to account for the crosstalk. The analysis of the reference cell provided the initial evidence and estimate of the crosstalk correction factor. Further refinement of the average correction factor at three different flight altitudes $(3.1,6.3$, and $12.7 \mathrm{~km})$ was obtained by ratioing the raw integrated pulse energies at wavelengths 1,2,4, and 5 to wavelength 3 and comparing the actual with the theoretical values. Obviously, the correction factor values for different altitudes are just average estimates, not exact values and they vary with altitude and topography. As the aircraft ascends or descends or the topography changes, the crosstalk factor will change. Furthermore, as the performance and gain of the OPO cavity change there is no guarantee that the crosstalk between wavelengths will remain fixed. The crosstalk correction factor accounted for the observed discrepancy for the three constant flight altitude segments of flight $3(3.1,6.3$, and $12.7 \mathrm{~km})$ and was applied to the analysis. Figure 12 shows the time series data of the in situ $\mathrm{CH}_{4}$ mixing ratio from the Picarro, the theoretical $\mathrm{CH}_{4}$ mixing ratio, set at $1900 \mathrm{ppb}$, and the retrieved $\mathrm{CH}_{4}$ mixing ratio values for the three constant flight altitude segments $(3.1,6.3$, and $12.7 \mathrm{~km}$ ) used in the analysis. When the outliers were removed, the standard deviation of the retrieved $\mathrm{CH}_{4}$ mixing ratio was $21.4 \mathrm{ppb}$ or $\sim 1.1 \%(21.4 / 1900 \mathrm{ppb})$. The DOD retrieval versus DOD theory linear fit (Fig. 13) had a slope of 1.01 and an offset of -0.003 . The $R^{2}$ value was 0.999 . These values are comparable but slightly worse than those obtained during flights 1 and 2 with the OPA, but the number of outliers that were filtered out was higher.

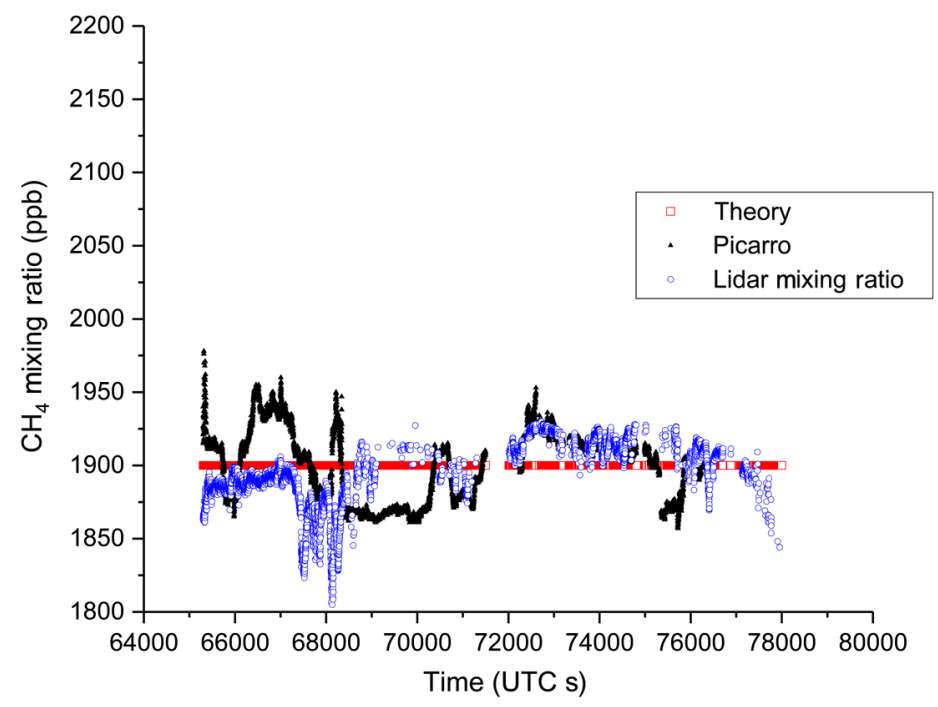

Fig. 12 Time series for flight 3 data showing the in situ $\mathrm{CH}_{4}$ mixing ratio as measured by the Picarro, the theoretical $\mathrm{CH}_{4}$ mixing ratio (set at $1900 \mathrm{ppbv}$ ), and the $\mathrm{CH}_{4}$ mixing ratio values by our retrieval algorithm. 


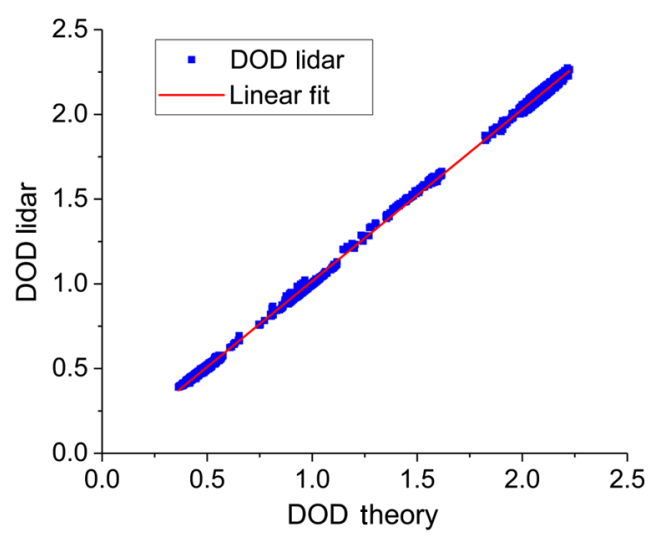

Fig. 13 Lidar DOD versus theoretical DOD for flight 3 . The linear fit had a slope of 1.01 and an offset of -0.003 . The $R^{2}$ value was 0.999 .

\section{Discussion}

The high accuracy and precision needed for $\mathrm{CH}_{4}$ measurements pose several challenges for the IPDA lidar design. Currently, the laser transmitter poses the greatest challenge. The transmitter must have narrow linewidth $(<100 \mathrm{MHz})$, must be tunable to scan over the $\mathrm{CH}_{4}$ absorption line $(\sim 250 \mathrm{pm})$, and must have high pulse energy. The exact energy requirement also depends on the detector QE, receiver aperture size, and other instrument parameters. Our link margin calculations show that $\sim 600 \mu \mathrm{J}$ is needed for space to achieve a $0.5 \%$ random error with a 1 -m diameter telescope.

We have tried to address several potential error sources in our instrument design: errors due to cloud and aerosol scattering are minimized by our pulsed approach, which digitizes the entire atmospheric column return and gates the returns from the ground. The IPDA lidar cannot penetrate optically thick clouds. However, our ranging algorithm provides accurate knowledge of the total pathlength minimizing the effect of multiple scattering and excluding returns from clouds. In order to improve the accuracy of the measurement, better knowledge of the spectroscopic parameters of the $\mathrm{CH}_{4}$ line and a more sophisticated lineshape function are needed. The $\mathrm{CH}_{4}$ line we used is actually comprised of multiple lines with different linestrengths and temperature dependence.

There are obvious differences between the instrument retrievals and those from the Picarro. The lidar values show less variation in the $\mathrm{CH}_{4}$ mixing ratio, which is to be expected since the Picarro is an in situ measurement and the lidar measures the column average. The Picarro recorded a significant increase in the in situ $\mathrm{CH}_{4}$ mixing ratio only for flight 1 despite the fact that we tried to target landfills and other areas of increased $\mathrm{CH}_{4}$ mixing ratios. No significant $\mathrm{CH}_{4}$ mixing ratio increase was observed near these areas by the Picarro for flights 2 and 3 . The biggest increase was observed during the spiral for flight 1 near the ground (around $7000 \mathrm{~s}$ UTC in Fig. 8) when the lidar was turned off to satisfy the laser safety requirements. The other big increase was observed earlier in the flight (around 6600 to $6700 \mathrm{~s}$ UTC in Fig. 8). The source of that increase is unclear.

The predicted values (i.e., "truth") to which our experimental data are fitted, assumed a constant $\mathrm{CH}_{4}$ mixing ratio of $1900 \mathrm{ppb}$. The actual $\mathrm{CH}_{4}$ mixing ratio profile over the entire flight path is of course, unknown. Although $1900 \mathrm{ppb}$ is clearly not an accurate estimate of the true mixing ratio for an entire flight, it provided a reasonable basis for estimating the precision, but not necessarily the absolute accuracy, of the IPDA lidar. In order to assess the accuracy of any IPDA lidar, multiple spirals and/or data from other sources such as radiosondes are needed to measure the actual vertical distribution of the $\mathrm{CH}_{4}$ mixing ratio. Even then, differences and biases will remain. Differences in the spectroscopic database (HITRAN 2012 versus 2008) and effects such as line mixing and speed-dependent profiles produce different results. Our incomplete knowledge of the state of the atmosphere (pressure, temperature, and humidity) and the accuracy of our meteorological model also contribute. Although the MERRA model was adequate for these initial demonstration flights, to evaluate the IPDA lidar accuracy, better 
knowledge and modeling of the state of the atmosphere and $\mathrm{CH}_{4}$ vertical profiles at the local level are needed. These can be obtained in future flights by increasing the frequency and location of the spirals, including data from other instruments and radiosonde data if available. Finally, lidar issues due to a variety of factors such as shot noise, ground reflectivity, speckle noise, wavelength, and power stability of the laser transmitter, etalon fringes, and in the case of the OPO cross talk between wavelengths all contribute to biases in the measurement. With the limited data obtained from these demonstration flights, we are not able to separate individual bias sources. However, we did observe that the random noise was reduced by the expected $1 / \sqrt{ } t_{\mathrm{av}}$, where $t_{\mathrm{av}}$ is the averaging time, for up to $\sim 5$ to $10 \mathrm{~s}$. After $\sim 5$ to $10 \mathrm{~s}$, no improvement in the noise statistics is observed.

The $\mathrm{CH}_{4}$ IPDA lidar needs significant engineering improvements to increase its reliability. The optomechanical design, laser transmitter stability, for both the OPA and OPO needs to be considerably improved to reduce the effects of vibration, temperature, and pressure. The locking electronics and diagnostics for the seed lasers and OPO cavity also need to improve. The isolation between $\mathrm{OPO}$ wavelengths needs to increase by at least an order of magnitude to eliminate the need for cross talk correction factors. All of these improvements are feasible if proper engineering resources can be applied.

The OPA, which used 20 wavelengths, produced better fits, was simpler to implement than the OPO because it did not require an optical resonator cavity, and was easier to align and tune. However, it is extremely difficult to scale the OPA energy to that needed for space ( $\sim 600 \mu \mathrm{J}$ depending on the receiver size and other instrument parameters) and maintain a narrow linewidth. The highest energy we obtained in the laboratory with our OPA was $290 \mu \mathrm{J}$ using a two-stage OPA, and the burst-mode $\mathrm{Yb}$ fiber laser amplified by a custom solid-state amplifier as a pump. However, at high energies, the OPA output spectrum typically consists of a sharp peak near the seed wavelength and a broad side lobe, when the parametric gain is high. In that case, we cannot clearly define the linewidth but it is generally too wide for accurate $\mathrm{CH}_{4}$ IPDA lidar measurements. In addition, for a space mission we are aiming for a simple and efficient single stage — not a complex multi-stage-OPA based on quasiphase matching (QPM). In this configuration, we have observed that the OPA output linewidth does not fully converge to the seed linewidth, giving wide side lobes, especially when pump and seed fluences are high and low, respectively. ${ }^{52}$ Similar side lobes were observed in the seeded QPM-based OPA system for a $\mathrm{CO}_{2}$ lidar. ${ }^{53}$ Back conversion and parametric amplification of the seed's side lobes are possible causes. Complex OPA/OPG systems in other wavelength regions have been developed with a narrow linewidth.$^{54}$ However, it is difficult to predict how they can be implemented with a multiwavelength IPDA lidar for space because of their complexity. If the seed laser power can be significantly scaled up then it may be possible to achieve energies of $600 \mu \mathrm{J}$ out of the OPA with a narrow linewidth. With the existing seed and pump laser technology, we do not see a path to space for the OPA in the near future. However, it remains a viable transmitter for $\mathrm{CH}_{4}$ measurements from an airborne platform.

In the OPO, narrow linewidth was achieved using an optical resonator cavity, which also enhances the energy of the nonlinear conversion. Our five-wavelength OPO uses a $1.2 \mathrm{~mJ}$ GSFC-built solid-state pump laser and a triangular optical ring cavity. We have since replaced the GSFC-built solid-state pump laser with a smaller, compact $\mathrm{Yb}$ fiber laser and redesigned the OPO cavity to improve stability. In the laboratory, we demonstrated energies of $\sim 250 \mu \mathrm{J}$ at $5 \mathrm{kHz}$ with a narrow (transform limited) linewidth. The OPO energy could be scaled to space but it requires complex optical phase-lock loops and cavity control.

In recent years, resonantly pumped erbium (Er) doped YAG, Er:YAG and Er:YGG, lasers, which directly emit at 1645.5 and $1650.96 \mathrm{~nm}$, respectively, offer another option for a $\mathrm{CH}_{4}$ transmitter. Using Er:YAG for $\mathrm{CH}_{4}$ detection dates back to $1972^{55}$ and recent successful demonstration and commercialization of high-power and high spectral brightness pump sources have afforded the realization of resonant pumping of Er:YAG ${ }^{56-59}$ and Er:YGG. ${ }^{60,61}$ The emission cross section of Er:YAG crystal is centered near $1645.3 \mathrm{~nm}$ and falls off rapidly at $1650.96 \mathrm{~nm}$. It is near the MERLIN lines at $1645.55 \mathrm{~nm}$, which are relatively wide ( $\sim 56 \mathrm{pm})$. Our $\mathrm{CH}_{4}$ line at $1650.96 \mathrm{~nm}$ is narrower $(\sim 36 \mathrm{pm})$, which makes fast tuning easier. Unfortunately, Er:YAG cannot be used as a gain medium at $1650.96 \mathrm{~nm}$, but Er:YGG can be used as a potential medium for lasing at that wavelength. Both materials are good candidates for 
a $\mathrm{CH}_{4}$ laser transmitter. Power scaling for both materials, multiwavelength operation and tuning considerations remain.

Our preliminary radiative transfer calculations show that both lines (Er:YAG at $1645.55 \mathrm{~nm}$ and Er:YGG at $1650.96 \mathrm{~nm}$ ) have similar temperature sensitivity and are well suited for space born $\mathrm{CH}_{4}$ measurements. Recent high-accuracy spectroscopic measurements indicate that line mixing effects in the Er:YAG $1645.55 \mathrm{~nm}$ line ${ }^{41}$ should also be taken into account. We expect similar effects to be present for the Er:YGG line at $1650.96 \mathrm{~nm}$.

\section{Summary}

We reported on an airborne demonstration of atmospheric $\mathrm{CH}_{4}$ measurements with an IPDA lidar using an OPO and OPA laser transmitter and sensitive avalanche photodiode detector. The lidar measured the atmospheric $\mathrm{CH}_{4}$ absorption at multiple, discrete wavelengths near $1650.96 \mathrm{~nm}$. The instrument was deployed in 2015 aboard NASA's DC-8 Airborne Laboratory and measured $\mathrm{CH}_{4}$ mixing ratios from 2 to $13 \mathrm{~km}$. Relatively high-precision measurements of $0.7 \%$ to $1.1 \%$ were demonstrated for all three flights; however, many areas of improvement remain. The stability and reliability of the laser transmitters need to improve considerably but the basic measurement approach has been demonstrated. We are currently improving our airborne instrument with better optomechanical design and compact, more stable laser transmitters. We hope to fly again in the near future when the next opportunity arises.

\section{Acknowledgments}

The authors would like to acknowledge the generous support by the Earth Science Technology Office (ESTO) Advanced Component Technology Program (ACT-13) and the GFSC Internal Research and Development (IRAD) Program. The authors would like to thank Dr. Piers Sellers, who passed away in December 2016, Ms. Lisa Callahan, and Dr. Matt Mcgill, for their unwavering support of our lidar development and flight demonstration. The authors would also like to thank Dr. Graham Allan and Dr. James Abshire for valuable discussions and consultations. The authors would also like to express their appreciation to the DC-8 flight operations team at the Science Aircraft Integration Facility in Palmdale, CA.

\section{References}

1. Intergovernmental Panel on Climate Change, IPCC Fifth Assessment Report, Cambridge University Press, Cambridge, New York (2013).

2. M. Saunois et al., "The global methane budget 2000-2012," Earth Syst. Sci. Data 8(2), 697-751 (2016)

3. E. Dlugokencky, "Trends in atmospheric methane," https://www.esrl.noaa.gov/gmd/ccgg/ trends_ch4/ (4 May 2017).

4. A. M. Fiore et al., "Linking ozone pollution and climate change: the case for controlling methane," Geophys. Res. Lett. 29(19), 1-4 (2002).

5. B. Franco et al., "Evaluating ethane and methane emissions associated with the development of oil and natural gas extraction in North America," Environ. Res. Lett. 11(4), 044010 (2016).

6. A. J. Turner et al., "A large increase in U.S. methane emissions over the past decade inferred from satellite data and surface observations," Geophys. Res. Lett. 43, 2218-2224 (2016).

7. National Research Council Decadal Survey, Earth Science and Applications from Space: National Imperatives for the Next Decade and Beyond, National Academic Press, Washington (2007).

8. D. Schimel et al., "Observing the carbon-climate system," arXiv preprint arXiv:1604.02106 (2016).

9. E. J. Dlugokencky et al., "Atmospheric methane at Mauna-Loa and Barrow observatoriespresentation and analysis of in-situ measurements," J. Geophys. Res. 100, 23103-23113 (1995). 
10. R. G. Prinn et al., "A history of chemically and radiatively important gases in air deduced from ALE/GAGE/AGAGE," J. Geophys. Res. 105(D14), 17751-17792 (2000).

11. E. A. G. Schuur et al., "Climate change and the permafrost carbon feedback," Nature 520(7546), 171-179 (2015).

12. P. F. Coheur et al., "Mid-upper tropospheric methane in the high Northern Hemisphere: spaceborne observations by AIRS, aircraft measurements, and model simulations," J. Geophys. Res. 115, D19309 (2010).

13. M. Buchwitz et al., "Atmospheric methane and carbon dioxide from SCIAMACHY satellite data: initial comparison with chemistry and transport models," Atmos. Chem. Phys. 5, 941-962 (2005).

14. P. Bergamaschi et al., "Satellite chartography of atmospheric methane from SCIAMACHY on board ENVISAT: 2. Evaluation based on inverse model simulations," J. Geophys. Res. 112, 1-26 (2007).

15. K. J. Wecht et al., "Validation of TES methane with HIPPO aircraft observations: implications for inverse modeling of methane sources," Atmos. Chem. Phys. 12, 1823-1832 (2012).

16. T. August et al., "IASI on Metop-A: operational level 2 retrievals after five years in orbit," J. Quantum Spectrosc. Radiat. Transf. 113, 1340-1371 (2012).

17. T. Yokota et al., "Global concentrations of $\mathrm{CO}_{2}$ and $\mathrm{CH}_{4}$ retrieved from GOSAT: first preliminary results," SOLA 5, 160-163 (2009).

18. D. Zona et al., "Cold season emissions dominate the Arctic tundra methane budget," Proc. Natl. Acad. Sci. U.S.A. 113(1), 40-45 (2016).

19. C. Stephan et al., "MERLIN: a space-based methane monitor," Proc. SPIE 8159, 815908 (2011).

20. M. Q. Kiemle et al., "Sensitivity studies for a space-based methane lidar mission," Atmos. Meas. Tech 4, 3545-3592 (2011).

21. R. Measures, Laser Remote Sensing, Chapter 7, John Wiley and Sons, New York (1984).

22. J. B. Abshire et al., "Airborne measurements of $\mathrm{CO}_{2}$ column absorption and range using a pulsed direct-detection integrated path differential absorption lidar," Appl. Opt. 52, 44464461 (2013).

23. G. Ehret et al., "Space-borne remote sensing of $\mathrm{CO}_{2}, \mathrm{CH}_{4}$, and $\mathrm{N}_{2} \mathrm{O}$ by integrated path differential absorption lidar: a sensitivity analysis," Appl. Phys. B 90, 593-608 (2008).

24. A. Amediek et al., "Development of an OPO system at $1.57 \mu \mathrm{m}$ for integrated path DIAL measurement of atmospheric carbon dioxide," Appl. Phys. B 92, 295-302 (2008).

25. H. Riris et al., "Airborne measurements of atmospheric methane column abundance using a pulsed integrated-path differential absorption lidar," Appl. Opt. 51, 8296-8305 (2012).

26. H. Riris et al., "Pulsed airborne lidar measurements of atmospheric optical depth using the oxygen A-band at $765 \mathrm{~nm}$," Appl. Opt. 52(25), 6369-6382 (2013).

27. G. D. Spiers et al., "Atmospheric $\mathrm{CO}_{2}$ measurements with a $2 \mu \mathrm{m}$ airborne laser absorption spectrometer employing coherent detection," Appl. Opt. 50(14), 2098-2111 (2011).

28. J. T. Dobler et al., "Atmospheric $\mathrm{CO}_{2}$ column measurements with an airborne intensitymodulated continuous wave $1.57 \mu \mathrm{m}$ fiber laser lidar," Appl. Opt. 52(12), 2874-2892 (2013).

29. A. Amediek et al., "CHARM-F-a new airborne integrated-path differential-absorption lidar for carbon dioxide and methane observations: measurement performance and quantification of strong point source emissions," Appl. Opt. 56, 5182-5197 (2017).

30. A. Fix et al., "Development and first results of a new near-IR airborne greenhouse gas lidar," in Optics and Photonics for Energy and the Environment, EM3A-3, Optical Society of America (2015).

31. A. Amediek et al., "First airborne IPDA lidar measurements of methane and carbon dioxide applying the DLR greenhouse gas sounder CHARM-F," in AGU Fall Meeting Abstracts (2015).

32. L. S. Rothman et al., "The HITRAN 2008 molecular spectroscopic database," J. Quantum Spectrosc. Radiat. Transf. 110(9), 533-572 (2009).

33. J. R. Chen, K. Numata, and S. T. Wu, "Error reduction in retrievals of atmospheric species from symmetrically measured lidar sounding absorption spectra," Opt. Express 22(21), 26055-26075 (2014). 
34. A. Ramanathan et al., "Spectroscopic measurements of a $\mathrm{CO}_{2}$ absorption line in an open vertical path using an airborne lidar," Appl. Phys. Lett. 103, 214102 (2013).

35. G. R. Allan et al., "Atmospheric backscatter profiles at $765 \mathrm{~nm}$ and $1572 \mathrm{~nm}$ from pulsed lidar measurements of $\mathrm{CO}_{2}$ and $\mathrm{O}_{2}$ column absorption from the 2013 ASCENDS flight campaign," in AGU Fall Meeting Abstracts, Vol. 1, p. 0211 (2013).

36. A. K. Ramanathan et al., "Remote sensing measurements of the $\mathrm{CO}_{2}$ mixing ratio in the planetary boundary layer using cloud slicing with airborne lidar," Geophys. Res. Lett. 42(6), 2055-2062 (2015).

37. K. Numata et al., "Ground demonstration of trace gas lidar based on optical parametric amplifier," J. Appl. Remote Sens. 6, 063561 (2012).

38. D. Engin et al., "Highly-efficient, high-energy pulse-burst Yb-doped fiber laser with transform limited linewidth," Proc. SPIE 9081, 908112 (2014).

39. K. Numata, H. Riris, and S. Wu, "Fast-switching methane lidar transmitter based on a seeded optical parametric oscillator," Appl. Phys. B 116(4), 959-966 (2014).

40. K. Numata, J. R. Chen, and S. T. Wu, "Precision and fast wavelength tuning of a dynamically phase-locked widely-tunable laser," Opt. Express 20(13), 14234-14243 (2012).

41. R. W. P. Drever et al., "Laser phase and frequency stabilization using an optical resonator," Appl. Phys. B 31, 97-105 (1983).

42. A. Fix et al., "Investigations on frequency and energy references for a space-borne integrated path differential absorption lidar," in Proc. of the Int. Conf. on Space Optics, Vol. 10 (2014).

43. J. Beck et al., "A highly sensitive multi-element HgCdTe e-APD detector for IPDA lidar applications," J. Electron. Mater. 43(8), 2970-2977 (2014).

44. X. Sun, J. B. Abshire, and J. D. Beck, "HgCdTe e-APD detector arrays with single photon sensitivity for space lidar applications," Proc. SPIE 9114, 91140K (2014).

45. X. Sun et al., "HgCdTe avalanche photodiode detectors for airborne and spaceborne lidar at infrared wavelengths," Opt. Express 25(14), 16589-16602 (2017).

46. J. B. Abshire et al., "Airborne measurements of $\mathrm{CO}_{2}$ column concentration and range using a pulsed direct-detection IPDA lidar," Remote Sens. 6, 443-469 (2014).

47. A. Amediek, X. Sun, and J. B. Abshire, "Analysis of range measurements from a pulsed airborne $\mathrm{CO}_{2}$ integrated path differential absorption lidar," IEEE Trans. Geosci. Remote Sens. 51(5), 2498-2504 (2013).

48. S. A. Clough and M. J. Iacono, "Line-by-line calculations of atmospheric fluxes and cooling rates: 2. Applications to carbon dioxide, ozone, methane, nitrous oxide, and the halocarbons," J. Geophys. Res. 100, 16519-16535 (1995).

49. T. Delahaye et al., "Precise methane absorption measurements in the $1.64 \mu \mathrm{m}$ spectral region for the MERLIN mission," J. Geophys. Res. 121(12), 7360-7370 (2016).

50. M. G. Bosilovich, "Regional climate and variability of NASA MERRA and recent reanalyses: U.S. summertime precipitation and temperature," J. Appl. Meteorol. Climatol. 52, 1939-1951 (2013).

51. M. M. Rienecker et al., "MERRA: NASA's modern-era retrospective analysis for research and applications," J. Clim. 24, 3624-3648 (2011).

52. S. Li et al., "Tunable narrow linewidth laser source for a methane lidar," in IEEE Aerospace Conf., pp. 1-8, IEEE (2012).

53. Y. Shibata, C. Nagasawa, and M. Abo, "Development of $1.6 \mu \mathrm{m}$ DIAL using an OPG/OPA transmitter for measuring atmospheric $\mathrm{CO}_{2}$ concentration profiles," Appl. Opt. 56(4), 1194-1201 (2017).

54. W. D. Kulatilaka et al., "Development of injection-seeded, pulsed optical parametric generator/oscillator systems for high-resolution spectroscopy," Appl. Phys. B 80(6), 669-680 (2005).

55. K. O. White and S. A. Schleusener, "Coincidence of Er:YAG laser emission with methane absorption at $1645.1 \mathrm{~nm}, "$ Appl. Phys. Lett. 21(9), 419-420 (1972).

56. X. Wang et al., "Dual-wavelength Q-switched Er:YAG laser around $1.6 \mu \mathrm{m}$ for methane differential absorption lidar," Laser Phys. Lett. 10(11), 115804 (2013).

57. P. Tang et al., "Stable and wavelength-locked Q-switched narrow-linewidth Er:YAG laser at 1645 nm," Opt. Express 23(9), 11037-11042 (2015). 
Riris et al.: Methane optical density measurements with an integrated path differential absorption...

58. H. Fritsche et al., "Resonantly diode pumped Er:YAG laser systems emitting at $1645 \mathrm{~nm}$ for methane detection," Laser Phys. Lett. 10(10), 105805 (2013).

59. C. Gao et al., " $6.1 \mathrm{~W}$ single frequency laser output at $1645 \mathrm{~nm}$ from a resonantly pumped Er:YAG nonplanar ring oscillator," Opt. Lett. 37(11), 1859-1861 (2012).

60. I. Kudryashov and E. Kotelnikov, "Tunable Q-switched solid state laser for methane detection," Proc. SPIE 10082, 100821I (2017).

61. J. M. Mackenzie et al., "Er:YGG planar waveguides grown by pulsed laser deposition for LIDAR applications," Proc. SPIE 10082, 100820A (2017).

Biographies for the authors are not available. 